\title{
Controlled Scalable Synthesis of ZnO Nanoparticles
}

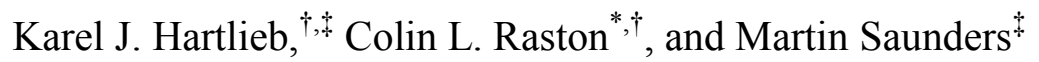 \\ ${ }^{\dagger}$ Centre for Strategic Nano-Fabrication, School of Biomedical, Biomolecular and \\ Chemical Sciences \\ ${ }^{\ddagger}$ Centre for Microscopy, Characterisation and Analysis, The University of Western \\ Australia, 35 Stirling Highway, Crawley WA 6009, Australia
}

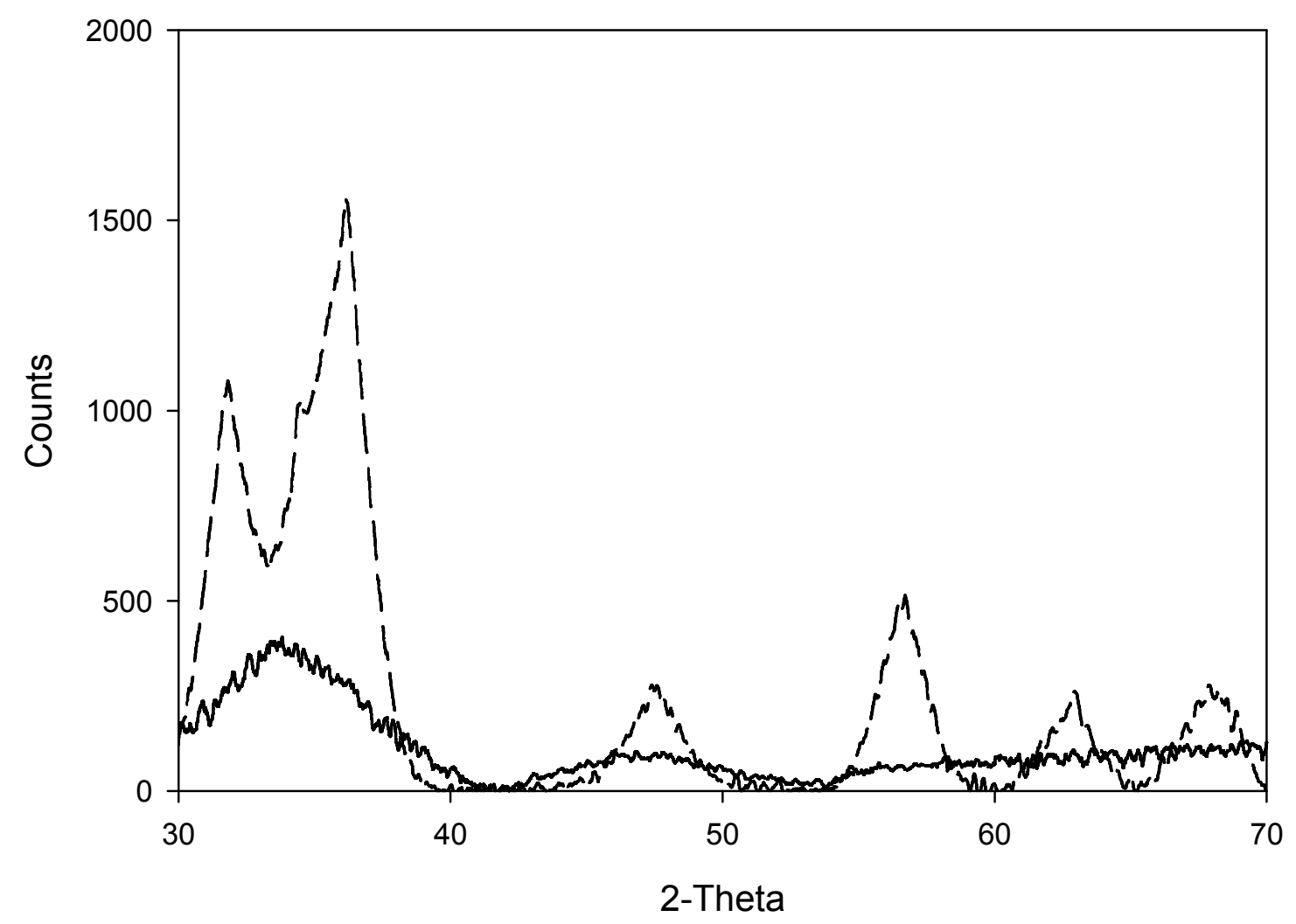

Figure S1. XRD patterns (background subtracted, $\mathrm{Cu} \mathrm{K \alpha _{2 }}$ stripped, and smoothed) of $\mathrm{Zn}: \mathrm{NaOH}: \mathrm{PVP} 10 \quad 1: 1: 0.05 \mathrm{wt} \%$ at $25^{\circ} \mathrm{C}$ and $3000 \mathrm{rpm},-\sim 1.4 \mathrm{~nm}$ particles, -..aged for one day (particle size $\sim 4 \mathrm{~nm}$ ) 


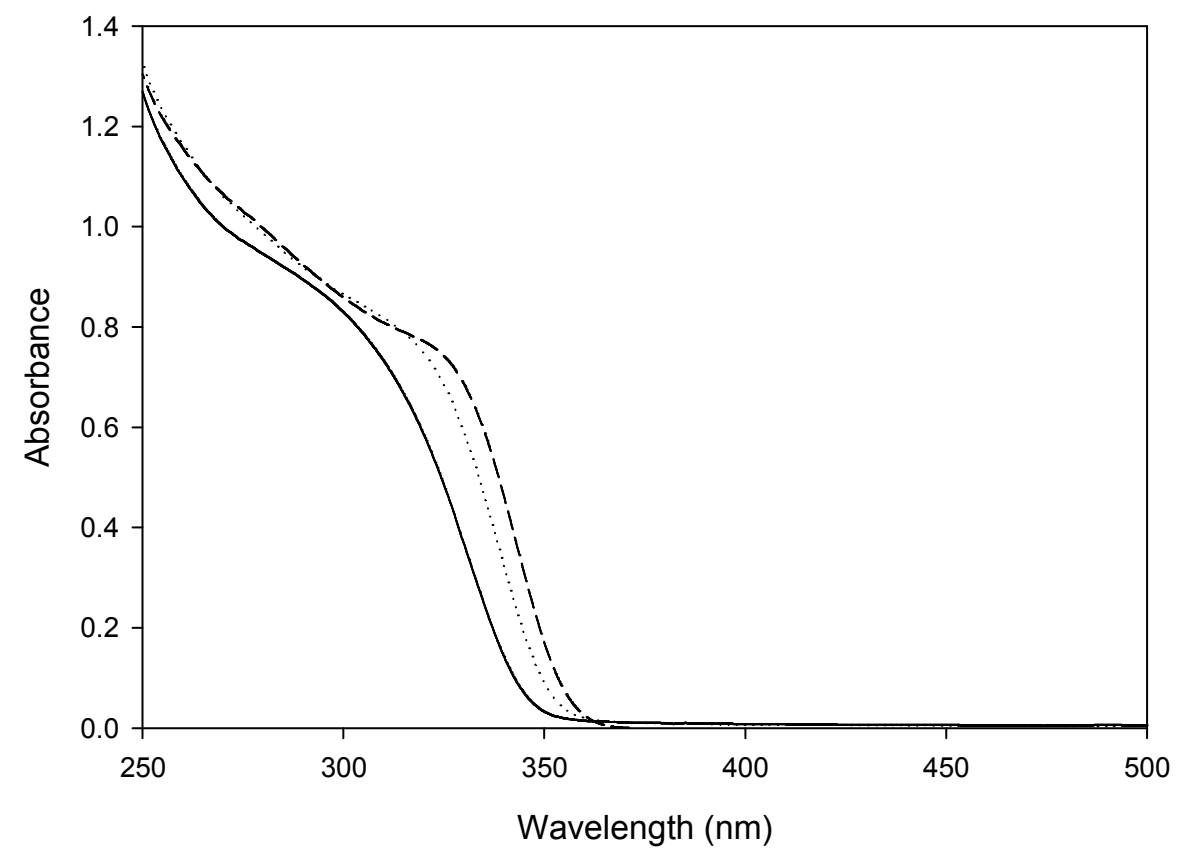

Figure S2. Ripening data of $\mathrm{Zn}: \mathrm{NaOH}: \mathrm{PVP} 10$ 1:1:0.05wt $\%$ synthesised at $80^{\circ} \mathrm{C}$ and 500 rpm after — 0 mins, ........ 1 hour, .... 1 day

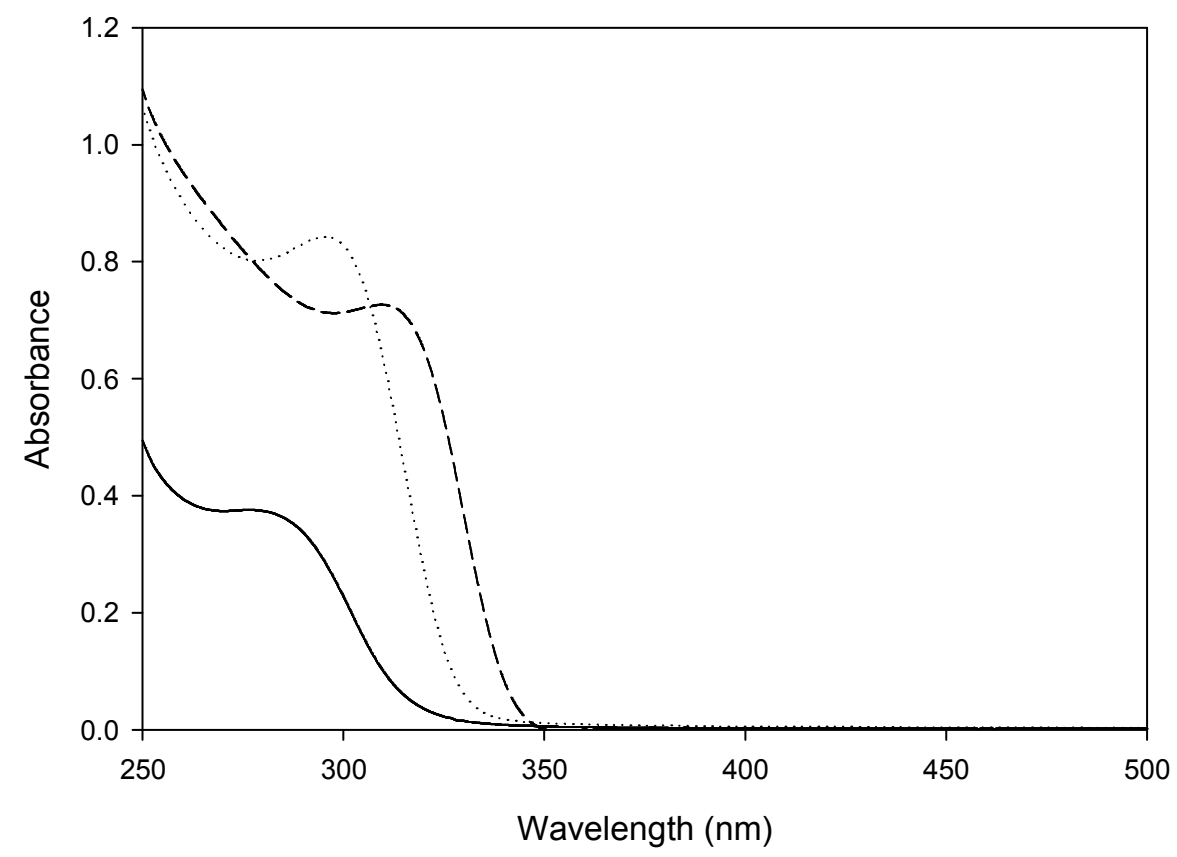

Figure S3. Ripening data of Zn:KOH:PVP10 1:1:0.05wt $\%$ synthesised at $80^{\circ} \mathrm{C}$ and 500 rpm after — 0 mins, ........ 1 hour, .... 1 day 